\title{
The Ameliorative Effect of Lactobacillus Paracasei BEJ01 Against FB1 Induced Spermatogenesis Disturbance, Testicular Oxidative Stress and Histopathological Damage
}

Khawla EZDINI ( $\square$ ezzdinikhawla@gmail.com ) Universite de Monastir

Jalila Ben salah-Abbès

University of Monastir: Universite de Monastir

Hela Belgacem

University of Monastir: Universite de Monastir

kamel chaieb

King Abdulaziz University Faculty of Sciences

Samir Abbès

University of Jendouba: Universite de Jendouba

\section{Research Article}

Keywords: Reprotoxicity, Fumonosin B1, oxidative stress, Sperm, testicles, Lactic Acid Bacteria

Posted Date: December 20th, 2021

DOI: https://doi.org/10.21203/rs.3.rs-1162613/v1

License: (c) (i) This work is licensed under a Creative Commons Attribution 4.0 International License.

Read Full License 


\section{Abstract}

Fumonisin B1 (FB1) was a possible carcinogenic molecule for humans as classified by the IARC on 2B group. In livestock, it was responsible for several mycotoxicosis and economic losses. Lactobacillus strains, inhabitants of a wide range of foodstuffs as well as our gastro-intestinal tract, were Generally Recognized as Safe (GRAS). Thus, the aim of this work was to evaluate the protective effect of Lactobacillus paracasei (LP) against FB1 induced reprotoxicities including testicular histopathology, sperm quality disturbance and testosterone level reduction.

Pubescent mice were divided randomly into four groups as bellow: Group1: Control; Group 2: FB1 (100

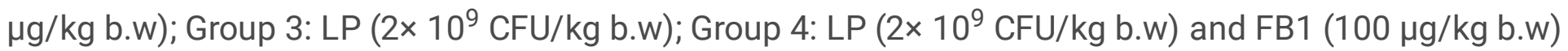
to be then treated for 10 days.

After the end of the treatment, animals were sacrificed; the plasma and epididyms and testicles were harvested to the reproductive system studies. Our results highlighted that LP counteracted the harmful effect generated by FB1. Indeed; it induced sperm quality reduction, oxidative stress generation and histological alterations.

In conclusion, the used strain was able to prevent FB1-reproductive system damages of in balb/c mice and could be valorised as an anti-cating agent in animal FB1-contaminated diet.

\section{Introduction}

Fumonisin $\mathrm{B} 1$, as one of the prevalent mycotoxins, produced by toxinogenic fungi such as $F$. verticilloides and $F$. moniliforme. It encountered naturally at high incidence in numerous foods and foodstuffs. In fact, FB1 is the most widely distributed Fusarium mycotoxins in North Africa (74\%). In particular, Jedidi et al., (2021) detected the abundance of fumonisins in $20.83 \%$ of wheat samples, $40 \%$ of barley and $57.14 \%$ of maize samples, at levels exceeding European limits and suggesting a risk for Tunisian cereals. Etiologically, it was reported that this toxin was linked with human's cancers and a class 2B was attributed by the IARC (IARC, 2002). Experimentally, its toxicity was associated with its analogy to sphingoids bases and the inhibition of ceramide synthase; a key enzyme in the biosynthesis of sphingolipids (Dellafiora et al, 2018). By consequence, a set of research concluded that FB1 leads to several pathologies in vivo and in vitro. In the one hand, the intestine, as a first defence of the microorganisms from toxicological substances, was affected with FB1 via the disturbance of Cyto P450 system and then a homeostasis imbalance as mentioned by Cao et al, (2020). In the other hand, the liver and kidney were also damaged even; they are specific hosts for FB1 accumulation (Hou et al, 2021; Demirel et al, 2015; Rumora et al, 2007). In the brain, FB1 was able to generate oxidative stress markers (Baldissera et al, 2020), neurochemistry toxicity (Gbore, 2010), facilitated seizures, as well as brain hyperexcitability (Poersh et al, 2015). Several studies reported also that FB1 induced immunotoxicity (Abbès et al, 2016), apoptosis (Zhang et al, 2018; Kim et al, 2018) and genotoxicity (Müller et al, 2012; Pinhão et al, 2020). 
Dietary exposure to FB1 may induce several physiological responses on the reproductive system. In previous studies, many authors were demonstrated that FB1 able to elevated ceramide levels causing an apoptotic effects on Leydig cells and testosterone production (Lu et al,2003; Szabó-Fodor et al. 2015). Further studies showed also, that this toxin affect granulosa cells proliferation and steroids production in swine and cattle species (Cortinovis et al, 2014; Albonico et al, 2016) leading to an ultimate influence of FB1 on female reproductive function. In the male, FB1 has been reported to have some adverse effects on reproduction in rats (Voss et al. 1996) and pigs (Harrison et al. 1990).

Relatively, few reports were available noting the FB1 effects on sperm quality, mobility and daily sperm production underlying to clarify FB1 reprotoxicity mechanism (Gbore and Egbunike, 2007; Ewuola and Egbunike, 2010a, 2010b; Minervini et al., 2010).

Recently, high concern has been attributed to mycotoxins bioavailability reduction in commodities using lactobacillus strains in vitro and in vivo studies regarding their abilities to release antifungal substances which could adsorb or degraded mycotoxins (Hassan et al, 2008; Honoré et al, 2016).

To consolidate these findings, the present report carry out about FB1 adverse effects on sperm parameters, daily sperm production and efficiency, testicular oxidative stress generation, histopathology of testis. Interestingly, we evaluated the protective effect of Lactobacillus paracasei BEJ01, Tunisian lactic acid bacteria, to mitigate the above cited FB1-reprotoxicities.

\section{Material And Methods}

\subsection{Chemicals and bacteria}

Pure Fumonisin B1 (FB1) (>98\% by HPLC) was obtained from Sigma Aldrich and stored in DMSO at $-80^{\circ} \mathrm{C}$. The working solution was obtained with dilution in sterile PBS (X1) and conserved at $+4^{\circ} \mathrm{C}$ in the working days. The used bacteria was Lactobacillus paracasei BEJ01 (LP BEJ01), lactic acid bacteria (LAB) isolated from Tunisian artisanal butter (Abbès et al., 2013). All the other chemicals used in this study were of analytical grade.

\subsection{Experimental animals}

Balb/c male pubescent mice purchased from the central pharmacy of Tunis (Siphat, Tunis) acclimatized before treatment to the following conditions: temperature of $23-25^{\circ} \mathrm{C}$, relative humidity and $12 \mathrm{~h}$ light/12h dark cycle. The animals are fed with free mycotoxins industrial granules and water ad libitium.

Experimental protocols were approved with the guidelines of the Ethical Committee of the High Institute of Biotechnology of Monastir, Tunisia

\subsection{Experimental design}

The mice were divided into 4 groups and treated for 10 days by oral gavage using a gastric tube as follows: 


\section{Group 1}

received $200 \mu$ of PBS

\section{Group 2}

$200 \mu \mathrm{l}$ of the solution LP BEJ01 $\left(2 \times 10^{9} \mathrm{CFU} \sim 2 \mathrm{mg} / \mathrm{kg} \mathrm{b.w}\right)$

\section{Group 3}

$200 \mu \mathrm{l}$ of the solution FB1 $(100 \mu \mathrm{g} / \mathrm{kg}$ b.w $)$

\section{Group 4}

$200 \mu \mathrm{l}$ of the solution containing FB1 $(100 \mu \mathrm{g} / \mathrm{kg} \mathrm{b.w})$ and $200 \mu \mathrm{l}$ of the solution containing LP BEJ01

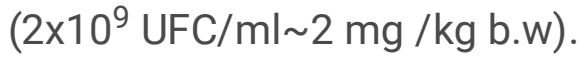

At the end of the treatment, mice were sacrificed and blood was collected by heart punction. Plasma was obtained after a cold centrifugation serving for the testosterone assay. Epididymis was freshly excised to be used for the sperm analysis. Right testis was stored at $-80^{\circ} \mathrm{C}$ for the oxidative markers while the left testis was taken for the histology study.

\subsection{Histology}

The: testis were taken by autopsy and immediately placed into the PFA (4\%) overnight for fixation. Then, they were dehydrated by an increasing serial concentration of ethanol followed by a step of tissue clarification by two baths of $n$-butanol before including the tissues in blocks of paraffin.

Sections 5 microns thick were made using a microtome. Ribbons containing serial sections of the organs will be mounted on slides, stained with H\&E to arrive finally for the microscopic examination.

\subsection{Epididymal Sperm analysis \\ 2.5.1. Sperm count and mobility}

The enumeration and mobility of epididymal semen were studied using the method of Linder et al., (1986). The epididymis tail was excised, chopped into a $1 \mathrm{ml}$ of the pre-incubated RPMI medium at $32^{\circ} \mathrm{C}$. The mixture was then incubated $\left(2 \mathrm{~min}, 32^{\circ} \mathrm{C}\right)$ and then diluted to $1 / 10$. A volume of $20 \mu \mathrm{l}$ will be used for counting on the hemocytometer cell. All spermatozoids were counted (mobile and non-mobile) in order to determine the mobile one of all the total spermatozoids number and then the percentage of mobility was determined. The microscopic exam was done at magnification $x 40$. Three replicate from each sample were done.

\subsubsection{Daily Sperm Production}


The daily sperm production (DSP) was assessed following the research protocol of Kyjovska et al, (2013) with such modifications. Indeed, the right testis was harvested after the sacrifice; its half was homogenized for 60 seconds at 13000 speeds in a saline solution containing $0.9 \% \mathrm{NaCl}$ and $0.05 \%$ triton $\mathrm{X}-100$. Only spermatids on the 14th and 16th stages will persist the mentioned homogenization to be counted after. To visualize them, staining with the Trypan blue $0.04 \%$ in PBS (1M) was done for 30 min before counting. The spermatids were counted with a light microscope at $400 \mathrm{x}$ magnification. The total elongated spermatids in the right testis were calculated by multiplication with the right testis weight.

DSP was calculated by dividing the total spermatids counted by 4.84 which correspond to the days that spent spermatids to develop into stage 14-16 in mouse species (Oakberg, 1956).

Then, the latter was divided by the weight of the testis to determine the number of sperm per gram of testis, which corresponds to the efficiency of sperm production.

\subsubsection{Sperm viability}

The viability of spermatozoids was assessed using the hypo-osmotic swelling (HOS) test described by Jeyendran et al., (1984) as a test for evaluating the functional integrity of the sperm membrane. This test is based on the homogenization of the epididymis head in $1 \mathrm{ml}$ of hypo-osmotic solution. The homogenate will then be incubated for 1 hour at $37^{\circ} \mathrm{C}$.

The microscopic observation was made at $\times 40$ magnification and an enumeration of 200 spzs was done per slide. 3 repetitions of each sample are made. The Viability was expressed as a percentage of viable spzs of the total number counted.

\subsubsection{Sperm morphology}

Other than the viability and mobility of the sperm, we also focus on the morphology of the spermatozoids which has been considered as an important fertility parameter. Indeed, a fragment of the epididymis was ground in $\mathrm{NaCl}$ saline solution (0.9\%) and formalin (10\%). Further, to this volume is added distilled water until $10 \mathrm{ml}$ is reached and then $1 \mathrm{ml}$ of eosin $1 \%$. Incubation at room temperature is requested between 40-120 min. A drop of the mixture is placed afterwards, spread between slide and coverslip serving for microscopic examination which allowed us to detect morphological abnormalities. The main focus is on the anomalies of the head and tail of the main parts of the spzs. 300 Spzs was counted per slide (3 replicate/sample). Each anomaly was expressed as a percentage of the total number counted.

\subsection{Testosterone assay}

The plasmatic testosterone concentration was determined by the competitive ELISA technique, according to the Demeditec Testosterone ELISA kit (Demeditec Diagnostics GmbH, REF: DE1559) instructions. The optic density (OD) was reading at $450 \mathrm{~nm}$ and the results have been calculated automatically using a 4 Parameter Logistics curve fit by an ELISA reader (『ayto, RT-2100C)

\subsection{Oxidative stress markers}


Testis samples from each group were homogenized into ice, centrifuged on cold for $15 \mathrm{~min}$ at $12000 \mathrm{rpm}$. The supernatant was stored at $-80^{\circ} \mathrm{C}$ until use while the cellular debris was thrown. The total protein content was assessed by the Bradford reagent in which we were focused to use the BSA to prepare the standard curve.

\subsubsection{Malondialdehyde}

The Malondialdehyde (MDA) was measured following the method described previously by Yoshioka et al, (1979). Indeed, a mixture of $100 \mu$ l of the testis homogenate, $2 \mathrm{ml}$ of TBA $(0.67 \%)$, and $800 \mu$ l of TCA $(20 \%)$ were heated on boiling bath of water for $30 \mathrm{~min}$. Centrifugation (4000 rpm, $10 \mathrm{~min}$ ) followed the cooling of the heated samples. Then, to obtain a pink colorant extract we add $3 \mathrm{ml}$ of $\mathrm{n}$-butanol. The absorbance of the supernatant was measured at $532 \mathrm{~nm}$ in parallel with a blank that contained the entire reagents except for the homogenate. The MDA concentration was expressed as the OD $(532 \mathrm{~nm})$ of the molar coefficient of extinction of the TBARS $(1.56 \times 105)$.

\subsubsection{Dienes conjugated}

The Dienes conjugated (DC) as one of the major lipid oxidation was assessed by the method of Ester Bauer et al., (1989). In fact, a mixture of $100 \mu$ homogenate, $1 \mathrm{ml}$ of $\mathrm{NaCl}(0.9 \%)$, and $3 \mathrm{ml}$ of chloroformmethanol (2v/1v) was vortexed for $2 \mathrm{~min}$ and then centrifuged (4000 rpm,10 min). The lower phase was transformed into a sterile tube to be evaporated into the oven $\left(70^{\circ} \mathrm{C}\right)$. Finally, we add $1 \mathrm{ml}$ of hexane and measure the OD at $243 \mathrm{~nm}$ in parallel with a blank (hexane). The DC was expressed on $\mu \mathrm{moles} / \mathrm{mg}$ of protein.

\subsubsection{Catalase:}

The catalase assay was carried out by measuring the decrease in absorbance at $240 \mathrm{~nm}$ of the sample for $1 \mathrm{~min}$. The Enzyme activity was expressed in $\mu$ moles of $\mathrm{H}_{2} \mathrm{O}_{2} / \mathrm{min} / \mathrm{mg}$ of protein. We adopt the protocol of Aebi, (1989).

\subsubsection{PSH}

The PSH activity was assessed as described by Sedlak and Lindsay, (1968). A mixture containing $50 \mu \mathrm{l}$ of homogenate, $150 \mu \mathrm{l}$ of $0.2 \mathrm{M}$ Tris ( $\mathrm{pH}=8.2$ ), $40 \mu \mathrm{l}$ of $0.02 \mathrm{M} \mathrm{EDTA}, 790 \mu \mathrm{l}$ of methanol, and $10 \mu \mathrm{l}$ of 0.01 M DTNB was incubated for $15 \mathrm{~min}$ to be then centrifuged for $\left(14500 \mathrm{rpm}, 10 \mathrm{~min}, 4^{\circ} \mathrm{C}\right)$. After a first record of the absorbance OD1 at $412 \mathrm{~nm}$, samples were supplemented with TCA (5\%) for the reason to precipitate the sulfhydryl proteins. Afterward, $300 \mu \mathrm{l}$ of the supernatant was incubated for $3 \mathrm{~min}$ after adding the $0.4 \mathrm{M}$ tris and 0.01 M DTNB. A second absorbance OD2 was done at the same wavelength as the OD1. In fact, the PSH content corresponds to subtract the OD2 (Containing the non-sulfhydril proteins) from OD1 (the total proteins). The reduced glutathione (GSH) was used to prepare a calibration curve. Finally, The PSH activity was expressed as nmoles/mg of protein.

\subsubsection{Carbonyl proteins}


As previously described by Colombo et al, (2016), we dose the carbonyl proteins as bellow:

A mixture tube containing $200 \mu \mathrm{l}$ of the homogenate, $800 \mu \mathrm{l}$ of DNPH dissolved into HCL $(2.5 \mathrm{~N})$ was incubated at room temperature in dark for $1 \mathrm{~h}$. A vortex every quarter of an hour was made. Then, we add $1 \mathrm{ml}$ of TCA (20\%) and re-incubate the tube on ice for $10 \mathrm{~min}$ followed by short centrifugation. The supernatant was discarded and the pellet was washed by TCA (10\%). New centrifugation was made and the pellet was washed with ethanol /ethyl acetate $(1 \mathrm{v} / 1 \mathrm{v})$. The final pellet was dissolved into $500 \mu \mathrm{l}$ of Guanidine hydrochloride $(6 \mathrm{M})$. The absorbance was recorded at $370 \mathrm{~nm}$ after incubating the mixture for 10 min at $37^{\circ} \mathrm{C}$.

\subsection{Statistic study}

The results of the in vivo study were statistically analyzed by the software SPSS IBM 23 using the test one-way ANOVA followed by Tukey as a posthoc test. All values expressed the mean \pm SD and the difference is significant at $p \leq 0.05$.

\section{Results}

\subsection{Histology}

The sections from the control testis (Fig. 1) showed that the testicular parenchyma was formed with seminiferous tubes (ST) separated by the interstitsium (I). ST was lined by spermatogonia, spermatocytes I, spermatids and a narrow lumen contains obvious mass of sperms. Animals treated with FB1 showed a vacuolation (V) and such debris in seminiferous tubules lumen, spermatocytes distorted resulting in a lack of sperm in the lumen. The interstitium containing vacuoles (wide interstitial space). LP alone showed a normal histology as the control. Combined to the FB1 was succedded to improve the above recorded alterations.

\subsection{The sperm concentration, viability, mobility and morphology}

Table 1 presented the sperm concentration, viability, mobitity and morphology of male balb/c mice in which the treated group with the FB1 decrease the sperm concentration $(101 \pm 22.5, p \leq 0.05)$ regarding the normal concentration of the control( $278 \pm 30.9, p \leq 0.05)$. Alone $(275 \pm 27, p \leq 0.05)$ or combined with the FB1 $(266 \pm 22, p \leq 0.05)$, the LP didn't affect the sperm number.

\section{Table 1}

Epididymal Sperm characteristics of adult mice issued from control, treated with FB1 and/or LP. 


\begin{tabular}{|lcccc|}
\hline Group & \multicolumn{4}{l|}{} \\
\hline Sperm parameters & Control & FB1 & LP & FB1+LP \\
\hline Concentration $\left(\times 10^{6} / \mathrm{ml}\right)$ & $278 \pm 30.9$ & $101 \pm 22.5^{\text {a }}$ & $275 \pm 27$ & $266 \pm 22$ \\
\hline Mobility (\%) & $58 \pm 8$ & $19 \pm 3^{\text {a }}$ & $63 \pm 4$ & $62 \pm 8$ \\
\hline Viability (\%) & $96 \pm 2$ & $72 \pm 13^{\text {a }}$ & $96 \pm 1$ & $94 \pm 2$ \\
\hline Abnormal Morphology (\%) & $13 \pm 2.4$ & $85 \pm 1.7^{\text {a }}$ & $10 \pm 0.3$ & $17 \pm 3.5$ \\
\hline $\begin{array}{l}\text { Data are expressed as mean } \pm \text { SD from } 6 \text { mice per group } \\
\text { a significantly different from the control (p < 0.05) }\end{array}$ \\
\hline
\end{tabular}

The sperm viability was also studied (table 1). The present data showed a slight decrease in the vitality (non-significant) of the treated mice sperm. The administration of LP alone or with the FB1 showed 95\% of viability as shown in the control group.

For mobility which was an important parameter in masculine fertility, our findings (Table 1) showed a decrease in the percentage of sperm mobility in the treated mice. The co-treated mice showed similar mobility as the control and the LP alone group showing a preventive effect on sperm motility affected by FB1 treatment.

Our results on the morphology of the epididymal spermatozoa (Fig. 2; 3 and 4) showed that FB1 affected the morphology of the spermatozoa with a high percentage of $85 \%$ compared to the other treated and control groups. In particular, a percentage of $60 \%$ was recorded as tail abnormalities in parallel with $25 \%$ of the head abnormalities (Fig. 3 and 4). Interestingly, administration of LP in combination with FB1 has shown restoration of these malformations caused by FB1-mycotoxin.

\subsection{DSP and DSP efficiency}

The DSP and DSP efficiency values were shown in table 2. Results didn't show any difference between the control $(25 \pm 2, p \leq 0.05)$ and LP group $(26 \pm 2, p \leq 0.05)$. Mice exposed to FB1 induced a significant decrease $(8 \pm 2, p \leq 0.05)$ in the DSP and DSP efficiency $(106 \pm 10, p \leq 0.05)$ compared to the control group $(359 \pm 39, p \leq 0.05)$. The co-treatment of LP with the FB1 showed a powerful effect to restore these altered parameters in the treated group.

Table 2

Testicular daily sperm production and efficiency on male balb/c mice 


\begin{tabular}{|lllll|}
\hline Group & & & & \\
\hline Parameters & Control & FB1 & LP & FB1+LP \\
\hline DSP/testis $\left(\times 10^{6}\right)$ & $25 \pm 2$ & $8 \pm 2^{\mathrm{a}}$ & $26 \pm 2^{\mathrm{b}}$ & $23 \pm 1^{\mathrm{b}}$ \\
\hline Efficiency (DSP/g of testis $\left(\times 10^{6}\right)$ & $359 \pm 39$ & $106 \pm 10^{\mathrm{a}}$ & $447 \pm 14^{\mathrm{b}}$ & $415 \pm 28^{\mathrm{b}}$ \\
\hline $\begin{array}{l}\text { Data are expressed as mean } \pm \text { SD from } 6 \text { mice per group } \\
\text { a Significantly different from the control (p < 0.05) }\end{array}$ & \\
\hline
\end{tabular}

\subsection{Testosterone level:}

Testosterone quantification by Elisa kit in the control, FB1, LP, and LP combined with FB1 groups was shown in figure 5. The plasmatic concentration observed in the LP group was similar to the control group. The exposure of animals to FB1 caused a notable decline in testosterone level. Combined with the FB1, the LP strain showed a potential effect to reverse the FB1 disturbance.

\subsection{Oxidative stress}

Results of the oxidative stress biomarkers (Fig. 6) showed that treatment of mice with LP alone didn't disturb the balance of the oxidative stress markers as compared with the control. The FB1 administration generated an oxidative stress via the increase of MDA, DC and PC accompanied with a decline of the CAT and PSH activities.

Inversely, the co-treatment with LP restored the failure of the oxidant system caused by FB1.

\section{Table 3}

Testicular MDA, DC, CAT, PC and PSH levels issued from control, treated with FB1 alone, LP alone and or combined with FB1. 


\begin{tabular}{|lllll|}
\hline Testis & Control & FB1 & LP & FB1+LP \\
\hline MDA (nmoles/mg of proteins) & $0.22 \pm 0.04$ & $0.54 \pm 0.03^{\mathrm{a}}$ & $0.22 \pm 0.04$ & $0.18 \pm 0.05$ \\
\hline DC (nmoles/mg of proteins) & $1.18 \pm 0.16$ & $2.24 \pm 0.2^{\mathrm{a}}$ & $1.28 \pm 0.2$ & $1.38 \pm 0.07$ \\
\hline CAT (nmoles/min/mg of proteins) & $0.24 \pm 0.02$ & $0.07 \pm 0.02^{\mathrm{a}}$ & $0.18 \pm 0.01$ & $0.23 \pm 0.01$ \\
\hline PSH (nmoles/mg of proteins) & $7.92 \pm 0.55$ & $1.8 \pm 0.2^{\mathrm{a}}$ & $6.58 \pm 0.5$ & $7.97 \pm 0.5$ \\
\hline PC (nmoles/mg of proteins) & $0.01 \pm 0.002$ & $0.023 \pm 0.003^{\mathrm{a}}$ & $0.008 \pm 0.002$ & $0.01 \pm 0.001$ \\
\hline $\begin{array}{l}\text { Data are expressed as mean } \pm \text { SD from } 6 \text { mice per group } \\
\text { a Significantly different from the control }(\mathrm{p}<0.05)\end{array}$ & & & \\
\hline
\end{tabular}

\section{Discussion}

Considering the deleterious effects and the economic losses caused by the contamination of crops by Fusarium fungi, great interest has been attributed to their mycotoxins in particular FB1. The later has adopted increasing attention in the scientific research in order to identify their health and economic problems as well as developing several strategies to reduce its spread in matrix used in alimentary chain for humain food and animal feed. Indeed, numerous harmful effects related to FB1-mycotoxin such as possible carcinogen for humans (IARC,2002), immunotoxic (Stoev et al., 2012b), neurotoxic (Suarez et al., 2012) and genotoxic (Chuturgoon et al., 2014a). In contrast, few reports about its affectation in male reproductive system were available. By consequence, the purpose of this study was aimed to evaluate FB1 effect on balb/c mice sperm quality, testosterone level, oxidative stress induction as well as histological alterations in the reproductive organs in part. In the other part and based to the consumer's demand to benefice about safe food (mycotoxins devoided), we were evaluate the lactobacillus paracasei BEJ01, to mitigate FB1-reprotoxicities. The mentionned bacteria were already used in our previous study and by itself was safe and shows potentiel protective effect against general toxicities (Ezdini et al,2020; abbès et al,2016).

In fact, mice exposed to FB1 during 10 days by an oral route showed a positive correlation between FB1 treatment and the reproductive system disturbance. Our results showed a testicular alterations marked by the presence of such debris and a vacuolization in the lamina of the seminiferous tubes. A wide interstitial space was also noted. 
These findings were in accordance with those of Abdelwaheb et al, (2018) in which reported that rats treated with FB1 (100 mg/kg b.w) showing vacuolation (V) in seminiferous tubules lumen, spermatocytes distorted, and the interstitium containing vacuoles and edematous spaces.

These tissular abnormalities may be attributed due to the toxin accumulation in the testis but also to the indirect effect of FB1 on disruption of cell membrane as a sphingolipids inhibitor.

Furthermore, the present data highlighted that this toxin affected the sperm parameters. First of all, the concentration of sperm was linked to the spermatogenesis happening that occurs in the seminiferous tubule and associated with the maturation of germ cells. As a consequence of the abnormalities located in the testis as described previously by the histological micrographs (fig. 1), the sperm concentration, daily sperm production and daily sperm production efficiency were significantly declined. The suggested mechanism of FB1 toward the spermatogenesis process was probably through its potential to elevate the sphingolipids contents which was associated to the apoptosis event. Here, we hypothesized that a germ cell apoptosis event occurs in the testicular epithelium as an effect of FB1 treatment leading to reduction of the germ cell population and hence reducing the studied parameters of the sperm quantity in both testis and epididymis. These findings could support the results suggested by Szabó-Fodor et al, (2015) in which they have been documented the disturbance of meiosis and mitosis of the germinal epithelial cells induced by FB1 alone or combined with ZEN and DON in rabbit buck.

Moreover, a slight reduction in the sperm vitality has been recorded in the treated mice. Then, a sharp decline of the mobility was also marked. In the main context, our results were supported by several studies. In fact, (Minervini et al., 2010) declared that FB1 reduced the total and progressive mobility of equine spermatozoa. Other, a similar phenomenon that affected spermatogenesis and sperm parameters were reported as a result of a dietary containing more than $5 \mathrm{mg} / \mathrm{kg}$ of FB1 in wild boar (Gbore and Egbunike, 2008). Likewise, livestock animals were affected as shown by Ewuola and Egbunike, (2010). In fact, Spermatic mass, motility and viability of the rabbit's semen declined in correlation with an increase in the dietary of FB1.

The mobility was sensitive to the morphology of the spermatozoa. Indeed, the mice exposure to FB1 has been shown to deleteriously affect the sperm morphology, in particular $60 \%$ of tail abnormalities and 25 $\%$ of head were recorded. The dominance of the tail abnormalities revealed the decline in the sperm motility mentioned before. How FB1 could significantly disturb the spermatogenesis and then the spermatozoa morphology? Two mechanisms were suggested, the first one was the reduction of the hormonal level in particular the testosterone quantity. Similar to ours, Abdelwaheb et al, (2018) have been showed the sensitivity of the testosterone level to the FB1 treatment alone or combined with AFB1. This hormonal disruption may be explained by the capability of FB1 to alter cholesterol and lipid homeostasis in the absence of LXR in the liver (Régnier et al.2019). An involvement of LPCAT3, a sphingolipid enzyme, was suggested in FB1 cholesterol modulation (Rong et al. 2013; Wang et al. 2016). In the same way, FB1 decreased LDLR and by consequence inhibited the cholesterol influx

(SheikAbdul and Chuturgoon, 2021).

Page $11 / 23$ 
Here, we suggest as a hypothesis that the established mechanism of FB1 affecting the cholesterol pathway in the liver could be adopted as the same in the Leydig cells via the absence of reports studying this detailed mechanism in the testis.

Second, we hypothesized that the ROS levels and their antioxidant defence imbalance led to an oxidative damage in the spermatozoa (Fraczek and kurisz, 2005). According to that we were focused to measure the oxidative stress occurred in the testis upon FB1 exposure. Our data spotlighted that the FB1 treatment elevated the MDA, DC and Proteins carbonyl levels. While, the catalase and PSH activities decreased.

The oxidative stress involved via the free radicals and peroxides generated give rise to damage the sperm membrane and decreased sperm motility. Thus, the shown abnormalities and impaired motility of sperm could be a result of the abnormal functionality of the mitochondria (Chai et al., 2017).

Several pathways may be involved in the effect of FB1 on the mitochondria generating the ROS. Due to its analogy to sphingolipids, FB1 was able to increase the polyunsaturated fatty acids content, trigger the mitochondrial permeability and then the induction of apoptosis.

These key mechanisms proposed were previously shown by (Aitken et al., 2012) which have been reported that ROS generation drives the spermatozoa along the intrinsic apoptotic cascade via the loss of Mitochondrial Membrane Potential leading to the DNA adduct formation, DNA fragmentation and ultimately cell death. In the main content, (NowickaBauer and Nixon, 2020) observed that ROS deregulated sperm bioenergetic pathways, along with the structural and signalling machineries of the sperm tail confirming the $60 \%$ of tail abnormalities founded in this study.

The supplementation of lactobacillus strain alone didn't cause any sign of toxicity and all the studied parameters showed a normal spermatogenesis as well as a good sperm quality in comparison with the normal group. Thus, several reports showed that lactobacillus strain benefit from a wide range of advantage effects. In fact, in previous studies, Lactobacillus was demonstrated to have a regulatory activity of cholesterol (Huang et al, 2020), a promoter effect to treat allergic rhinitis (Güvenç et al, 2016). Also, they have also shown anti-inflammatory (Abbès et al, 2016), antifungal (Mundula et al, 2019), antimicrobial (Pattani et al, 2013), antiviral (Lehtoranta et al, 2014) effects.

Supplemented to the FB1, our strain showed powerful protective effects against FB1 toxicities on the reproductive system in mice. In fact, the ROS generation, as one promising prospective that can be a diagnostic of the sperm physiopathology and structure. Then, the preventive effect of lactobacillus on FB1 spermatogenesis toxicities was thanks to its antioxidants activities playing a key role on improving the sperm motility via its ion pumps present in the flagella. Sertoli cells benefit also from the powerful antioxidant activities of probiotics boosting the survival and maturation of spermatozoa (Inatomi and Otomaru, 2018). Experimentally, several in vitro and in vivo studies showed that probiotics, in particular, lactobacillus strain enhanced antioxidant enzymes via chelating Fe2+ and Cu2+ (Lee et al., 2005), reduced ROS imbalance and by consequence counteracted apoptosis pathways (Yan and Polk, 2002; Wu et al., 2019). Likewise, probiotics dietary effectively protect spermatogenic cells, sperm quality and then 
protect the reproductive system (Chen et al., 2013; Valcarce et al., 2019; Abasi and Keshtmand, 2020). Another study realized by (Dardmeh et al., 2017) demonstrated a positive correlation between the regulation of cholesterol by probiotics and the plasmatic level of testosterone.

Finally, other excepted mechanism popularly suggested in probiotics counteracting mycotoxins by sequestration and/or degradation in the gastrointestinal tract (zhao et al, 2016, Vanhoutte et al, 2017, Ben Salah Abbès et al., 2020).

\section{Conclusion}

To conclude, our findings showed that male reproductive system was threaten by FB1 enhancing oxidative stress damage leading to deleteriously affect sperm parameters, reducing testosterone level and testicular histological alterations. Protective effects showed by lactobacillus paracasei supplementation to FB1 intoxicated mice. It could be added as a good prospective against mycotoxins disturbing the reproductive system via its antioxidant power.

Further molecular investigations in probiotics metabolites on spermatogenesis improvement would be recurred.

\section{Declarations}

\section{Ethics approval and consent to participate}

Experimental protocols were approved with the guidelines of the Ethical Committee of the High Institute of Biotechnology of Monastir, Tunisia.

\section{Conflicts of Interest:}

The authors declare no conflict of interest.

\section{Acknowledgement}

This research work was funded by Institutional Fund Projects under grant no (IFPIP-372-130-1442). Therefore, the authors gratefully acknowledge technical and financial support from the Ministry of Education and King Abdulaziz University, Jeddah, Saudi Arabia.

\section{Authors Contributions}

Khawla Ezdini: Methodology, Writing, Original draft, Jalila Ben Salah- Abbès: Data curation, Writing. Hela Belgacem: Visualization, Investigation. Kamel Chaieb: review \& editing. Samir Abbès: Supervision, Writing 
\& editing.

Animal Welfare Statement: The authors confirm that the ethical policies of the journal, as noted on the journal's author guidelines page, have been adhered to. No ethical approval was required as this is a meta-analysis article with no original research data.

\section{References}

1. Abasi, S., \& Keshtmand, Z. (2020). The effect of probiotic Bifidobacterium lactis and Lactobacillus casei on sperm maturation in streptozotocin-diabetic rats. ISMJ, 22(6), 392-401.

2. Abbès ,S., Ben Salah-Abbes, J., Jebali, R., Younes, R.B., Oueslati, R. Interaction of aflatoxin B1 and fumonisin B1 in mice causes immunotoxicity and oxidative stress: Possible protective role using lactic acid bacteria. Immunotoxicol.13,46-54 (2016).

3. Abbès,S., Ben Salah-Abbes, J., Sharafi ,H., Oueslati, R., Noghabi, K.A. Lactobacillus paracasei BEJ01 prevents immunotoxic effects during chronic zearalenone exposure in Balb/c mice. Immunopharm.Immunotox. 35,341-348 (2013).

4. Abdel-Wahhab, M. A., El-Nekeety, A. A., Hassan, N. S., Gibriel, A. A., \& Abdel-Wahhab, K. G. (2018). Encapsulation of cinnamon essential oil in whey protein enhances the protective effect against single or combined sub-chronic toxicity of fumonisin B 1 and/or aflatoxin B 1 in rats. Environmental Science and Pollution Research, 25(29), 29144-29161.

5. Abdul, N. S., \& Chuturgoon, A. A. (2021). Fumonisin B1 regulates LDL receptor and ABCA1 expression in an LXR dependent mechanism in liver (HepG2) cells. Toxicon, 190, 58-64.

6. Aebi, H .Catalase. In: Bergmer HU (ed) Methods in enzymatic analysis. Acad.New.York. 2,673-684 (1974).

7. Aitken, R. J., Whiting, S., De luliis, G. N., McClymont, S., Mitchell, L. A., \& Baker, M.

A. (2012). Electrophilic aldehydes generated by sperm metabolism activate mitochondrial reactive oxygen species generation and apoptosis by targeting succinate dehydrogenase. Journal of Biological Chemistry, 287(39), 33048-33060.

8. Albonico, M., Schütz, L. F., Caloni, F., Cortinovis, C., \& Spicer, L. J. (2016). Toxicological effects of fumonisin B1 alone and in combination with other fusariotoxins on bovine granulosa cells. Toxicon, 118, 47-53.

9. Baldissera, M. D., Souza, C. F., da Silva, H. N. P., Henn, A. S., Duarte, F. A., da Costa, S. T., ... \& Baldisserotto, B. (2020). Diphenyl diselenide modulates splenic purinergic signaling in silver catfish fed diets contaminated with fumonisin B1: An attempt to improve immune and hemostatic responses. Comparative Biochemistry and Physiology Part C: Toxicology \& Pharmacology, 227, 108624.

10. Cao,C., Zhu ,X., Li, X., Ouyang,H., Wang ,K.,Li,X. Assessment of ionic homeostasis imbalance and cytochrome $\mathrm{P} 450$ system disturbance in mice during fumonisin B1 (FB1) exposure. Chemosphere.251 (2020). 
11. Chai, R. R., Chen, G. W., Shi, H. J., O, W. S., Martin-Deleon, P. A., \& Chen, H. (2017). Prohibitin involvement in the generation of mitochondrial superoxide at complex I in human sperm. Journal of cellular and molecular medicine, 21(1), 121-129.

12. Chen, X. L., Gong, L. Z., \& Xu, J. X. (2013). Antioxidative activity and protective effect of probiotics against high-fat diet-induced sperm damage in rats. Animal, 7(2), 287-292.

13. Chuturgoon, A., Phulukdaree, A., \& Moodley, D. (2014). Fumonisin B1 induces global DNA hypomethylation in HepG2 cells-An alternative mechanism of action. Toxicology, 315, 65-69.

14. Colombo,G., Clerici, M., Garavaglia,M.E., Giustarini,D., Ross, R., Milzani, A., Dalle-Donne, I. A step-bystep protocol for assaying protein carbonylation in biological samples. J.Chrom .B.1019,178-190 (2016).

15. Cortinovis, C., Caloni, F., Schreiber, N. B., \& Spicer, L. J. (2014). Effects of fumonisin B1 alone and combined with deoxynivalenol or zearalenone on porcine granulosa cell proliferation and steroid production. Theriogenology, 81(8), 1042-1049.

16. Dardmeh, F., Alipour, H., Gazerani, P., van der Horst, G., Brandsborg, E., \& Nielsen, H. I. (2017). Lactobacillus rhamnosus PB01 (DSM 14870) supplementation affects markers of sperm kinematic parameters in a diet-induced obesity mice model. PLoS One, 12(10), e0185964.

17. Dellafiora, L., Galaverna, G., \& Dall'Asta, C. (2018). Mechanisms of fumonisin B1 toxicity: a computational perspective beyond the ceramide synthases inhibition. Chemical research in toxicology, 31(11), 1203-1212.

18. Demirel, G., Alpertunga, B., \& Ozden, S. (2015). Role of fumonisin B1 on DNA methylation changes in rat kidney and liver cells. Pharmaceutical biology, 53(9), 1302-1310.

19. Diagn Investig 2:217-221

20. Esterbauer,H., Striegl, G., Puhl H., Oberreither S., Rotheneder, M., EL-SAADANI ,M.O., Jürgens, G.The Role of Vitamin E and Carotenoids in Preventing Oxidation of Low Density Lipoproteins a. Ann.New.York.Acad. Sci.570,254-267 (1989).

21. Ewuola, E. O., \& Egbunike, G. N. (2010). Effects of dietary fumonisin B1 on the onset of puberty, semen quality, fertility rates and testicular morphology in male rabbits. Reproduction, 139(2), 439.

22. Ewuola, E. O., \& Egbunike, G. N. (2010). Gonadal and extra-gonadal sperm reserves and sperm production of pubertal rabbits fed dietary fumonisin B1. Animal reproduction science, 119(3-4), 282286.

23. Ezdini, K., Salah-Abbès, J. B., Belgacem, H., Mannai, M., \& Abbès, S. (2020). Lactobacillus paracasei alleviates genotoxicity, oxidative stress status and histopathological damage induced by Fumonisin B1 in BALB/c mice. Toxicon, 185, 46-56.

24. Fraczek, M., \& Kurpisz, M. (2005). The redox system in human semen and peroxidative damage of spermatozoa. Postepy higieny i medycyny doswiadczalnej (Online), 59, 523-534.

25. Gbore, F. A. (2010). Brain and hypophyseal acetylcholinesterase activity of pubertal boars fed dietary fumonisin B1. Journal of animal physiology and animal nutrition, 94(5), e123-e129. 
26. Gbore, F. A., \& Egbunike, G. N. (2008). Testicular and epididymal sperm reserves and sperm production of pubertal boars fed dietary fumonisin B1. Animal Reproduction Science, 105(3-4), 392397.

27. Güvenç, I. A., Muluk, N. B., Mutlu, F. Ş., Eşki, E., Altıntoprak, N., Oktemer, T., \& Cingi, C. (2016). Do probiotics have a role in the treatment of allergic rhinitis? A comprehensive systematic review and Metaanalysis. American journal of rhinology \& allergy, 30(5), e157-e175.

28. Harrison LR, Colvin BM, Greene JT, Newman LE, Cole JR (1990) Pulmonary oedema and hydrothorax in swine produced by fumonisin B1, a toxic metabolite of Fusarium moniliforme. J Vet

29. Hassan, Y. I., \& Bullerman, L. B. (2008). Antifungal activity of Lactobacillus paracasei subsp. tolerans against Fusarium proliferatum and Fusarium graminearum in a liquid culture setting. Journal of food protection, 71(11), 2213-2216.

30. Honoré, A. H., Aunsbjerg, S. D., Ebrahimi, P., Thorsen, M., Benfeldt, C., Knøchel, S., \& Skov, T. (2016). Metabolic footprinting for investigation of antifungal properties of Lactobacillus paracasei. Analytical and bioanalytical chemistry, 408(1), 83-96.

31. Hou, L., Yuan, X., Le, G., Lin, Z., Gan, F., Li, H., \& Huang, K. (2021). Fumonisin B1 induces nephrotoxicity via autophagy mediated by $\mathrm{mTORC} 1$ instead of mTORC2 in human renal tubule epithelial cells. Food and Chemical Toxicology, 149, 112037.

32. Huang, Y., Xiao, Y., Song, L., Chu, Q., Zhu, S., Ren, Z., \& Li, X. (2020). Effects of Lactobacillus paragasseri $Y 20$ on cholesterol-lowering, intestinal microbiota and liver metabolism in rats with hypercholesterolaemia. Wei Sheng yan jiu= Journal of Hygiene Research, 49(4), 574-579.

33. IARC. 2002. Some traditional herbal medicines, some mycotoxins, naphthalene and styrene. 82 ,IARC , Lyon,France.

34. Inatomi, T., \& Otomaru, K. (2018). Effect of dietary probiotics on the semen traits and antioxidative activity of male broiler breeders. Scientific reports, 8(1), 1-6.

35. Jedidi, I., Mateo, E. M., Marín, P., Jiménez, M., Said, S., \& González-Jaén, M. T. (2021). Contamination of wheat, barley and maize seeds with toxigenic Fusarium species and their mycotoxins in Tunisia. Journal of AOAC International.

36. Jeyendran, R. S., Van der Ven, H. H., Perez-Pelaez, M., Crabo, B. G., \& Zaneveld, L. J. D. (1984). Development of an assay to assess the functional integrity of the human sperm membrane and its relationship to other semen characteristics. Reproduction, 70(1), 219-228.

37. Kim,S.H., Singh,M.P., Sharma,C., Kang, S.C. Fumonisin B1 actuates oxidative stress-associated colonic damage via apoptosis and autophagy activation in murine model. J.Bioch.Mol.Toxicol. 32,22161 (2018).

38. Kyjovska, Z.O., Boisen, A.M.Z., Jackson, P., Wallin, H., Vogel, U. and Hougaard, K.S., 2013. Daily sperm production: application in studies of prenatal exposure to nanoparticles in mice. Reproductive Toxicology, 36, pp.88-97.

39. Lee, J., Hwang, K. T., Chung, M. Y., Cho, D. H., \& Park, C. S. (2005). Resistance of Lactobacillus casei KCTC 3260 to reactive oxygen species (ROS): role for a metal ion chelating effect. Journal of food 
science, 70(8), m388-m391.

40. Lehtoranta, L., Pitkäranta, A., \& Korpela, R. (2014). Probiotics in respiratory virus infections. European journal of clinical microbiology \& infectious diseases, 33(8), 1289-1302.

41. Linder, R. E., Hess, R. A., \& Strader, L. F. (1986). Testicular toxicity and infertility in male rats treated with 1, 3-dinitrobenzene. Journal of Toxicology and Environmental Health, Part A Current Issues, 19(4), 477-489.

42. Lu, Z. H., Mu, Y. M., Wang, B. A., Li, X. L., Lu, J. M., Li, J. Y., ... \& Nawata, H. (2003). Saturated free fatty acids, palmitic acid and stearic acid, induce apoptosis by stimulation of ceramide generation in rat testicular Leydig cell. Biochemical and biophysical research communications, 303(4), 1002-1007.

43. Minervini, F., Lacalandra, G. M., Filannino, A., Garbetta, A., Nicassio, M., Dell'Aquila, M. E., \& Visconti, A. (2010). Toxic effects induced by mycotoxin fumonisin B1 on equine spermatozoa: Assessment of viability, sperm chromatin structure stability, ROS production and motility. Toxicology in vitro, 24(8), 2072-2078.

44. Müller, S., Dekant, W., \& Mally, A. (2012). Fumonisin B1 and the kidney: Modes of action for renal tumor formation by fumonisin B1 in rodents. Food and chemical toxicology, 50(10), 3833-3846.

45. Mundula, T., Ricci, F., Barbetta, B., Baccini, M., \& Amedei, A. (2019). Effect of probiotics on oral candidiasis: a systematic review and meta-analysis. Nutrients, 11(10), 2449.

46. Nowicka-Bauer, K., \& Nixon, B. (2020). Molecular changes induced by oxidative stress that impair human sperm motility. Antioxidants, 9(2), 134.

47. Oakberg EF. Duration of spermatogenesis in the mouse and timing of stages of the cycle of the seminiferous epithelium. American Journal of Anatomy. 1956 Nov;99(3):507-16.

48. Pattani, R., Palda, V. A., Hwang, S. W., \& Shah, P. S. (2013). Probiotics for the prevention of antibioticassociated diarrhea and Clostridium difficile infection among hospitalized patients: systematic review and meta-analysis. Open Medicine, 7(2), e56.

49. Pinhão, M., Tavares, A. M., Loureiro, S., Louro, H., Alvito, P., \& Silva, M. J. (2020). Combined cytotoxic and genotoxic effects of ochratoxin $A$ and fumonisin B1 in human kidney and liver cell models. Toxicology in Vitro, 68, 104949.

50. Poersch, A. B., Trombetta, F., Souto, N. S., de Oliveira Lima, C., Braga, A. C. M., Dobrachinski, F., ... \& Furian, A. F. (2015). Fumonisin B1 facilitates seizures induced by pentylenetetrazol in mice. Neurotoxicology and teratology, 51, 61-67.

51. Régnier, M., Polizzi, A., Lukowicz, C., Smati, S., Lasserre, F., Lippi, Y., ... \& Loiseau, N. (2019). The protective role of liver $X$ receptor $(L X R)$ during fumonisin B1-induced hepatotoxicity. Archives of toxicology, 93(2), 505-517.

52. Rong, X., Albert, C. J., Hong, C., Duerr, M. A., Chamberlain, B. T., Tarling, E. J., ... \& Tontonoz, P. (2013). LXRs regulate ER stress and inflammation through dynamic modulation of membrane phospholipid composition. Cell metabolism, 18(5), 685-697.

53. Rumora, L., Domijan, A. M., Grubišić, T. Ž., \& Peraica, M. (2007). Mycotoxin fumonisin B1 alters cellular redox balance and signalling pathways in rat liver and kidney. Toxicology, 242(1-3), 31-38. 
54. Sedlak, J., Lindsay, R.H. Estimation of total, protein-bound, and nonprotein sulfhydryl groups in tissue with Ellman's reagent. Analy.bioch.25,192-205 (1968).

55. Stoev, S. D., Gundasheva, D., Zarkov, I., Mircheva, T., Zapryanova, D., Denev, S., ... \& Schneider, Y. J. (2012). Experimental mycotoxic nephropathy in pigs provoked by a mouldy diet containing ochratoxin A and fumonisin B1. Experimental and Toxicologic Pathology, 64(7-8), 733-741.

56. Suarez, L., Felkner, M., Brender, J. D., Canfield, M., Zhu, H., \& Hendricks, K. A. (2012). Neural tube defects on the Texas-Mexico border: What we've learned in the 20 years since the Brownsville cluster. Birth Defects Research Part A: Clinical and Molecular Teratology, 94(11), 882-892.

57. Szabó-Fodor J, Kachlek M, Cseh S, Somoskői B, Szabó A, Bodnár ZB,Tornyos G, Mézes M, Balogh K, Glávits R, Hafner D, Kovács M (2015) Individual and combined effects of subchronic exposure of

58. three Fusarium toxins (Fumonisin B, Deoxynivalenol and Zearalenone) in rabbit bucks. Clin Toxicol $5: 415$

59. Valcarce, D. G., Riesco, M. F., Martínez-Vázquez, J. M., \& Robles, V. (2019). Diet supplemented with antioxidant and anti-inflammatory probiotics improves sperm quality after only one spermatogenic cycle in zebrafish model. Nutrients, 11(4), 843.

60. Vanhoutte, I., De Mets, L., De Boevre, M., Uka, V., Di Mavungu, J. D., De Saeger, S., ... \& Audenaert, K. (2017). Microbial Detoxification of Deoxynivalenol (DON), Assessed via a Lemna minor L. Bioassay, through Biotransformation to 3-epi-DON and 3-epi-DOM-1. toxins, 9(2), 63.

61. Voss, K. A., Bacon, C. W., Norred, W. P., Chapin, R. E., Chamberlain, W. J., Plattner, R. D., \& Meredith, F. I. (1996). Studies on the reproductive effects of Fusarium moniliforme culture material in rats and the biodistribution of [14C] fumonisin B1 in pregnant rats. Natural Toxins, 4(1), 24-33.

62. Wang, B., Rong, X., Duerr, M. A., Hermanson, D. J., Hedde, P. N., Wong, J. S., ... \& Tontonoz, P. (2016). Intestinal phospholipid remodeling is required for dietary-lipid uptake and survival on a high-fat diet. Cell metabolism, 23(3), 492-504.

63. Wu, Y., Wang, B., Xu, H., Tang, L., Li, Y., Gong, L., ... \& Li, W. (2019). Probiotic Bacillus attenuates oxidative stress-induced intestinal injury via p38-mediated autophagy. Frontiers in microbiology, 10, 2185.

64. Yan, F., \& Polk, D. B. (2002). Probiotic bacterium prevents cytokine-induced apoptosis in intestinal epithelial cells. Journal of biological chemistry, 277(52), 50959-50965.

65. Yoshioka, T., Kawada, K., Shimada, T., Mori, M. Lipid peroxidation in maternal and cord blood and protective mechanism against activated-oxygen toxicity in the blood. Americ.J.Obst.Gyn.135,372-376 (1979).

66. Zhang, W., Zhang, S., Zhang, M., Yang, L., Cheng, B., Li, J., \& Shan, A. (2018). Individual and combined effects of Fusarium toxins on apoptosis in PK15 cells and the protective role of $\mathrm{N}$ acetylcysteine. Food and Chemical Toxicology, 111, 27-43.

67. Zhao, H., Wang, X., Zhang, J., Zhang, J., \& Zhang, B. (2016). The mechanism of Lactobacillus strains for their ability to remove fumonisins B1 and B2. Food and Chemical Toxicology, 97, 40-46. 
68. Kyjovska, Z.O., Boisen, A.M.Z., Jackson, P., Wallin, H., Vogel, U. and Hougaard, K.S., 2013. Daily sperm production: application in studies of prenatal exposure to nanoparticles in mice. Reproductive Toxicology, 36, pp.88-97.

69. Oakberg EF. Duration of spermatogenesis in the mouse and timing of stages of the cycle of the seminiferous epithelium. American Journal of Anatomy. 1956 Nov;99(3):507-16.

70. Aitken, R. J., Whiting, S., De luliis, G. N., McClymont, S., Mitchell, L. A., \& Baker, M. A. (2012). Electrophilic aldehydes generated by sperm metabolism activate mitochondrial reactive oxygen species generation and apoptosis by targeting succinate dehydrogenase. Journal of Biological Chemistry, 287(39), 33048- 33060.

71. Chai, R.-R., Chen, G.-W., Shi, H.-J., O, W.-S., Martin-DeLeon, P. A., \& Chen, H. (2017). Prohibitin involvement in the generation of mitochondrial superoxide at complex I in human sperm. Journal of Cellular and Molecular Medicine, 21(1), 121- 129.

72. Domijan, A. M., \& Abramov, A. Y. (2011). Fumonisin B1 inhibits mitochondrial respiration and deregulates calcium homeostasis-implication to mechanism of cell toxicity. The international journal of biochemistry \& cell biology, 43(6), 897-904.

73. Mundula, T., Ricci, F., Barbetta, B., Baccini, M., \& Amedei, A. (2019). Effect of probiotics on oral candidiasis: a systematic review and meta-analysis. Nutrients, 11(10), 2449.

74. Lehtoranta, L., Pitkäranta, A., \& Korpela, R. (2014). Probiotics in respiratory virus infections. European journal of clinical microbiology \& infectious diseases, 33(8), 1289-1302.

75. Pattani, R., Palda, V. A., Hwang, S. W., \& Shah, P. S. (2013). Probiotics for the prevention of antibioticassociated diarrhea and Clostridium difficile infection among hospitalized patients: systematic review and meta-analysis. Open Medicine, 7(2), e56.

\section{Figures}



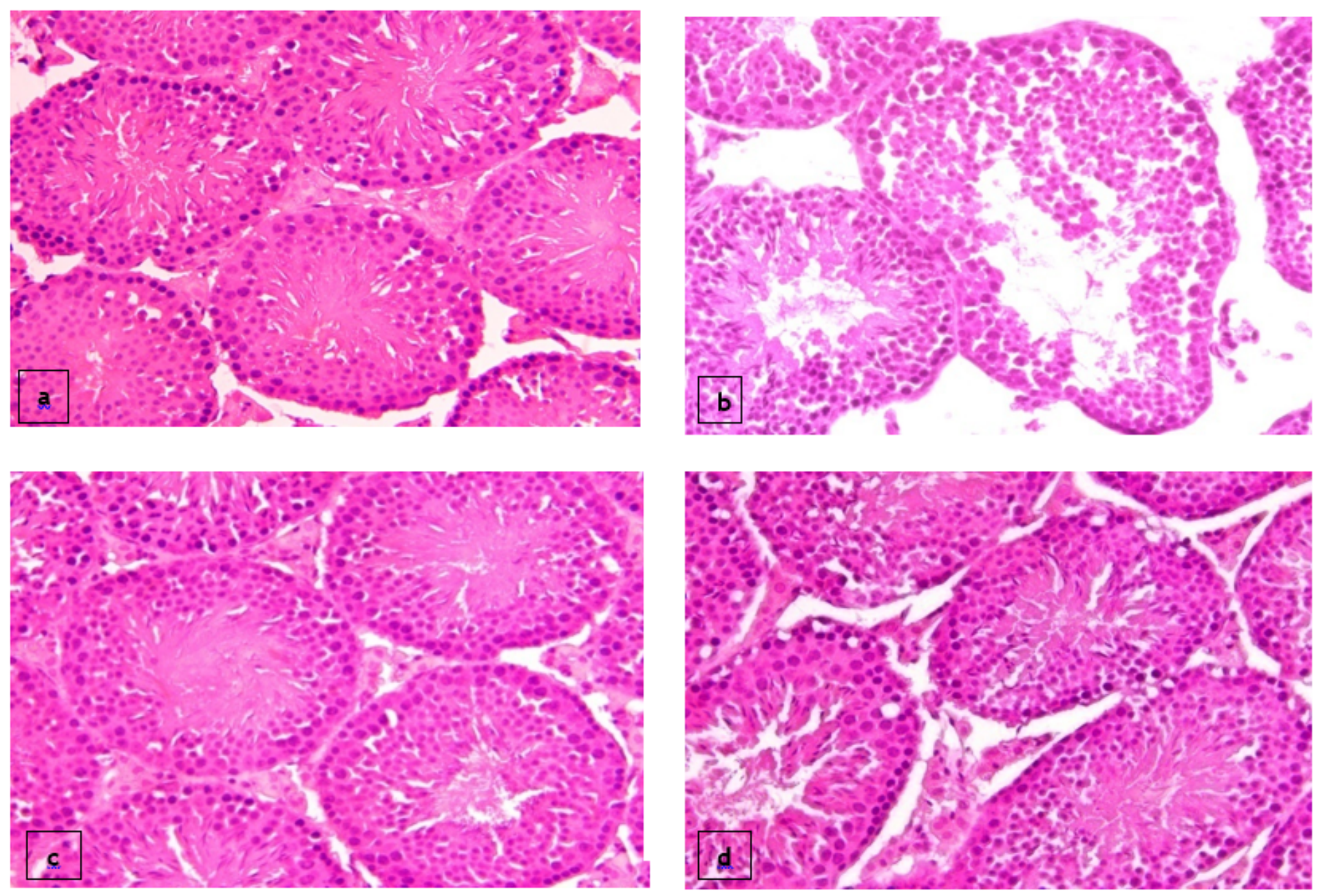

Figure 1

Microphotographs section of testicles of control mice (a), exposed to Fumonisin B1 (b), Lactobacillus alone (c) and Combined (LP+FB1) (d) for 10 days stained with hematoxylin \& eosin (Magnification: $\mathbf{X}$ 400) 


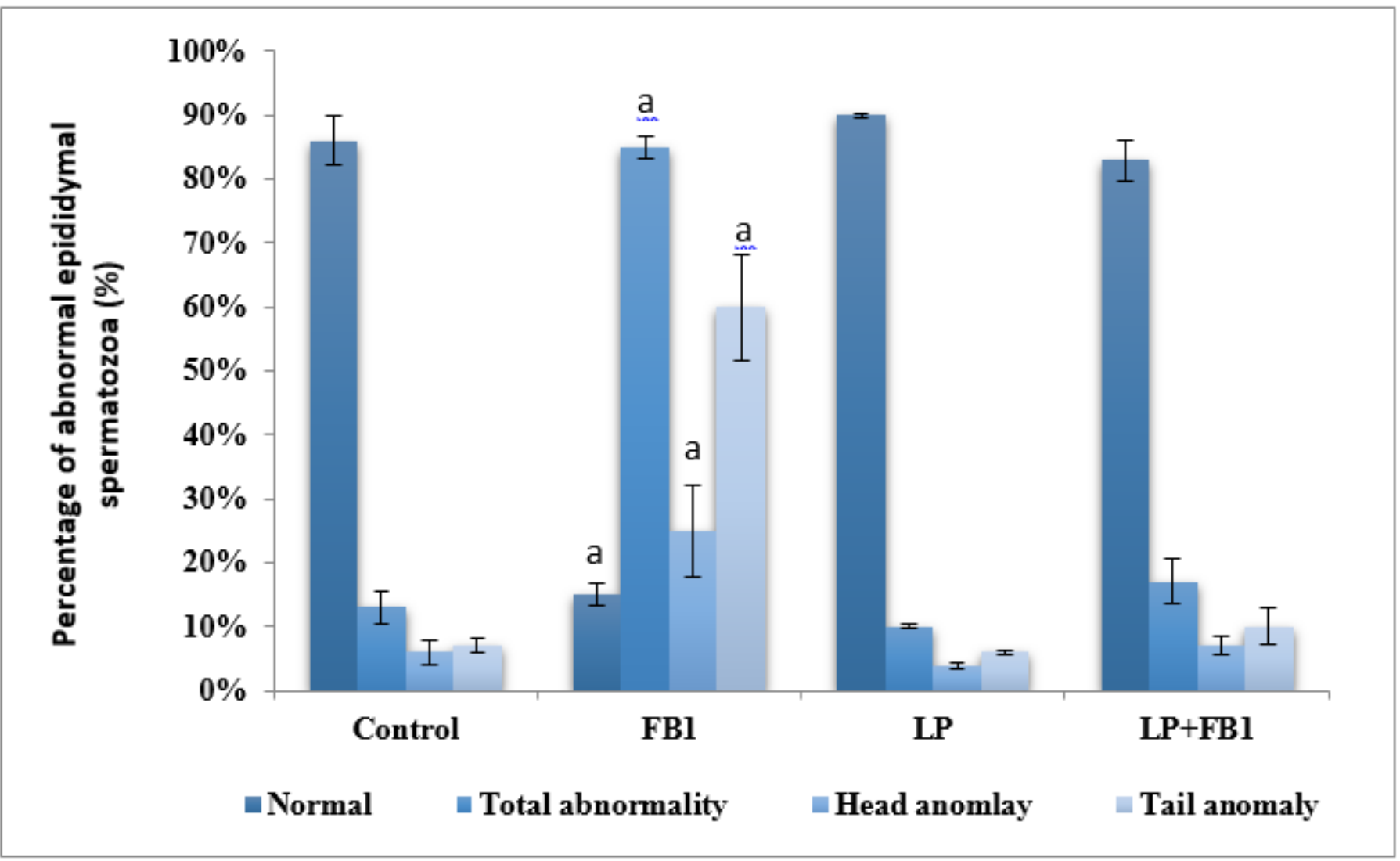

Figure 2

Spermatozoa morphology: Normal, total abnormality, head abnormality and tail abnormality issued from control, treated with FB1 and/or LP.

Data are expressed as mean \pm SD from 6 mice per group

a Significantly different from the control $(p<0.05)$
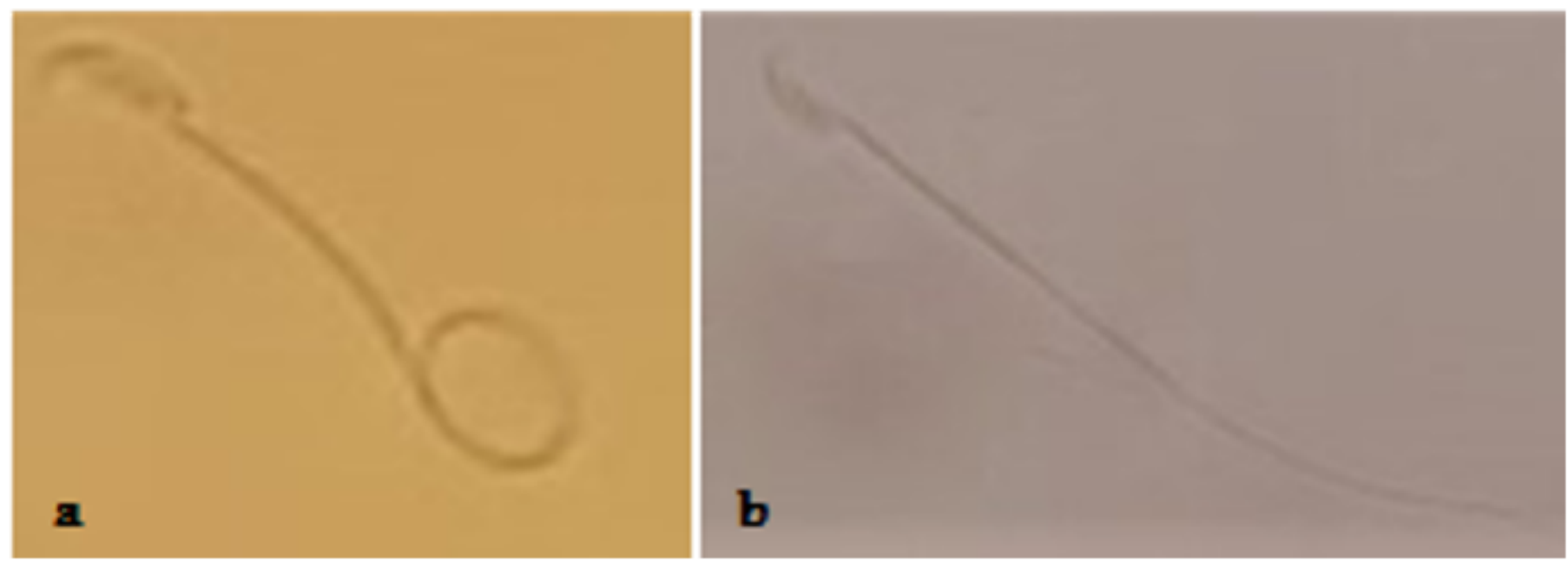

Figure 3 
Viable and dead spermatozoa detected in FB1-treated mice
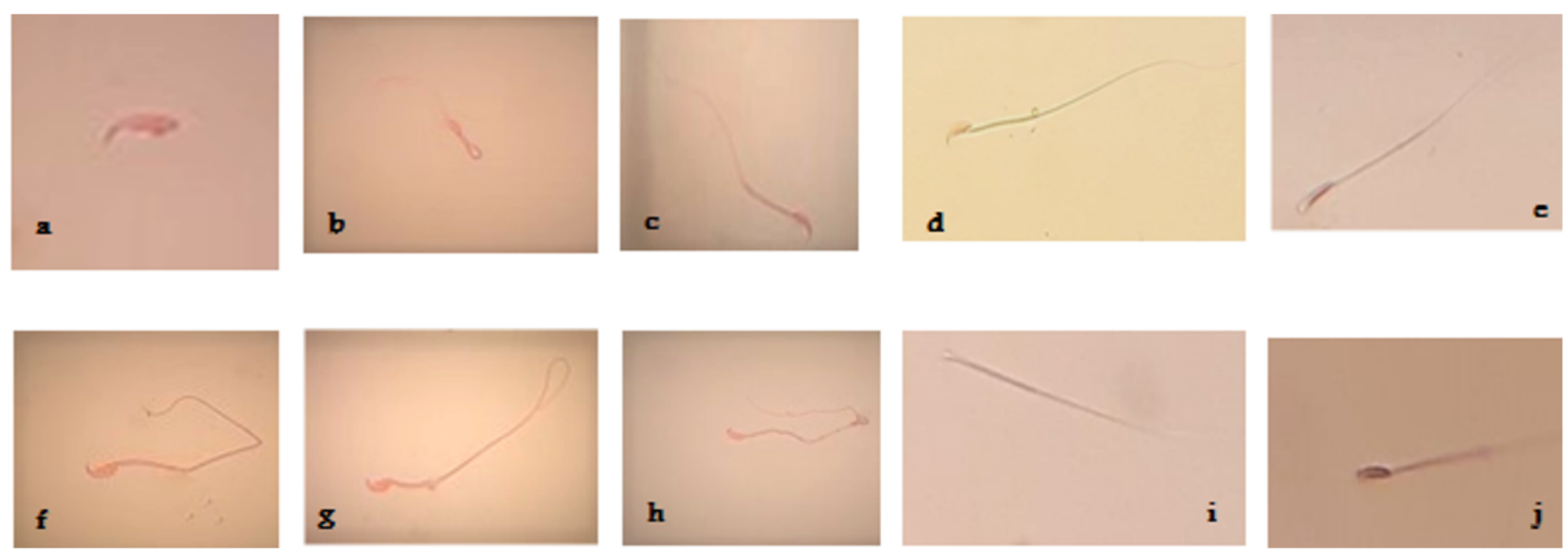

\section{Figure 4}

Different morphology of spermatozoa evaluated in all groups 


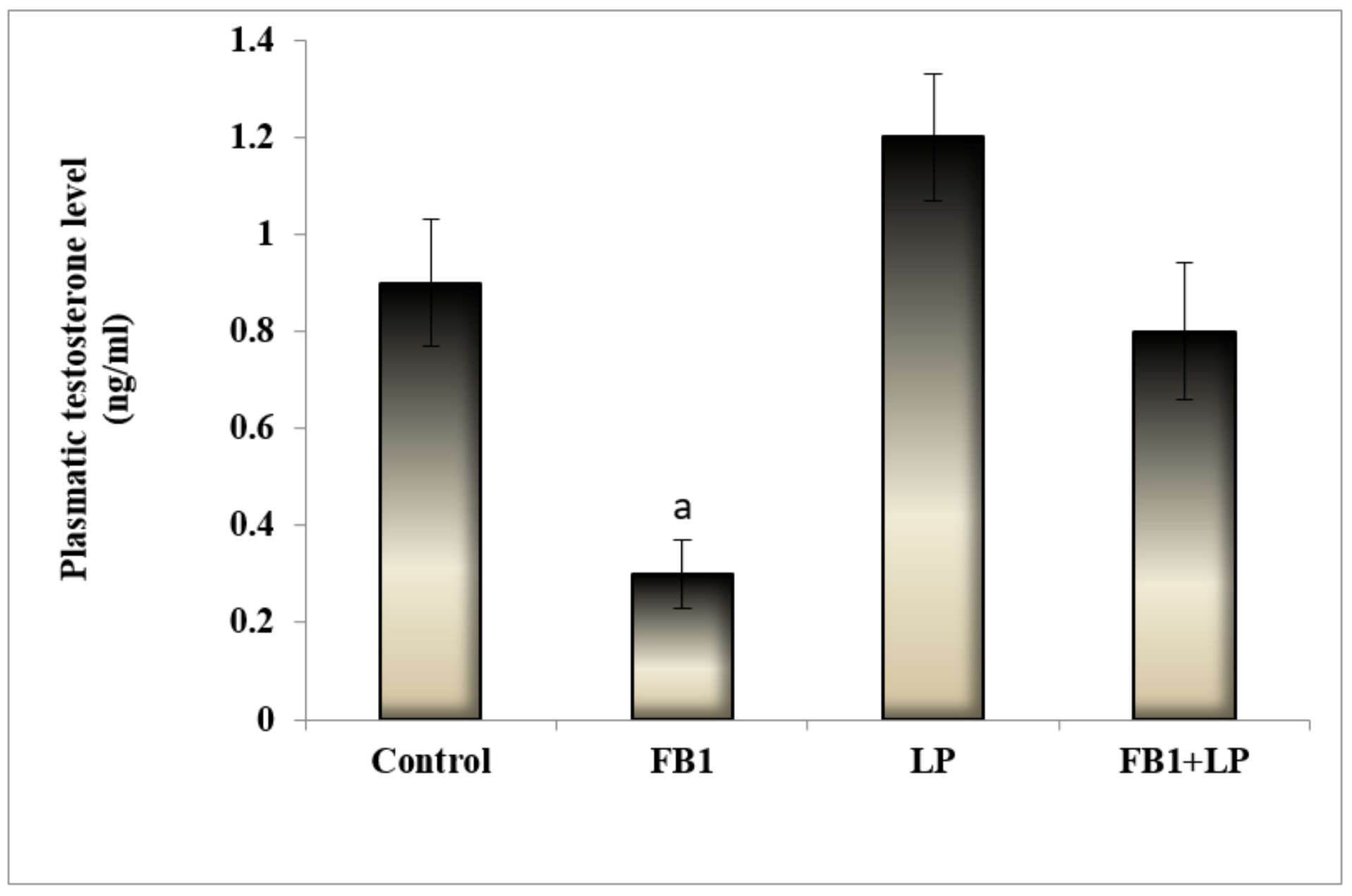

Figure 5

Plasmatic testosterone level of control, treated with FB1 alone, LP alone and FB1 +LP.

Data are expressed as mean \pm SD from 6 mice per group

a Significantly different from the control $(p<0.05)$ 